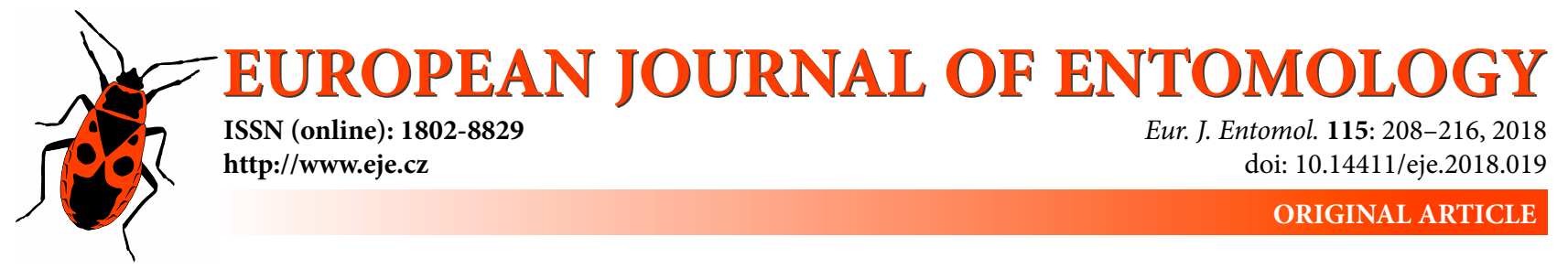

\title{
Laboratory rearing of Sycanus annulicornis (Hemiptera: Reduviidae) on two species of prey: Differences in its biology and efficiency as a predator of the nettle caterpillar pest Setothosea asigna (Lepidoptera: Limacodidae)
}

\author{
AbDul SAHID ${ }^{1}$, WAHYU D. NATAWIGENA ${ }^{2}$, HERSANTI ${ }^{2}$ and SUDARJAT ${ }^{2}$ \\ ${ }^{1}$ Agroecotechnology Study Program, Agricultural Faculty, Mulawarman University, Jalan Pasir Belengkong, P.O. Box 1040, \\ Samarinda, East Kalimantan 75119, Indonesia; e-mail: asahid69@gmail.com \\ ${ }^{2}$ Agroecotechnology Study Program, Agricultural Faculty, Padjadjaran University, Jl. Raya Bandung - Sumedang KM. 21 \\ Jatinangor 45363, Indonesia; e-mails: daradjat327@gmail.com, hersanti09@gmail.com, ajat_proteksi@yahoo.com
}

Key words. Hemiptera, Reduviidae, Sycanus annulicornis, Lepidoptera, Limacodidae, Setothosea asigna, laboratory rearing, Crocidolomia pavonana, Tenebrio molitor, different prey diets, biological parameters, predatory ability

\begin{abstract}
Setothosea asigna van Eecke is a dominant defoliator pest in oil palm plantations. To control this pest, a generalist predatory bug, Sycanus annulicornis Dohrn, was used as it is easy to rear on several different species of prey. In this study, we evaluated the influence of different prey on the biology and the ability of $S$. annulicornis to attack and kill the nettle caterpillar pest S. asigna. Based on laboratory rearing, the larvae of Crocidolomia pavonana F. (Lepidoptera: Crambidae) is a suitable prey for both the growth and development of $S$. annulicornis, as its nymphal development is shorter (74.0 \pm 7.3 days) and adult longevity longer ( $81.0 \pm 9.0$ days for male and $64.8 \pm 12.4$ days for female, respectively) than when reared on the larvae of Tenebrio molitor L. (Coleoptera: Tenebrionidae) (44.0 \pm 16.7 days for male and $52.6 \pm 14.4$ days for female). However, $S$. annulicornis reared on T. molitor larvae attacked 2.0-2.2 larvae of $S$. asigna per day, which is more than the 1.6-1.7 larvae per day of those reared on C. pavonana, which indicates that the larvae of $T$. molitor are a more effective diet for rearing $S$. annulicornis as biocontrol agent for the S. asigna.
\end{abstract}

\section{INTRODUCTION}

Oil palm, Elaeis guineensis Jacq, is an important oil crop introduced to meet the vegetable oil needs of Indonesia. The main factor limiting the oil palm productivity in Indonesia is existence of the nettle caterpillar, which defoliates oil palm (Kalidas, 2012). Outbreaks of nettle caterpillars cause serious damage to oil palm plantations in Indonesia and Malaysia (Kalshoven, 1981). The nettle caterpillar pest most commonly found in oil palm plantations, particularly in East Kalimantan and generally in Southeast Asia, is $\mathrm{Se}$ tothosea asigna (Lepidoptera: Limacodidae) (Cock et al., 1987; Lay, 1996). S. asigna attacks both young and old oil palm plantations with heavy infestation causing yield losses of $70 \%$ in the first year after defoliation and $90 \%$ when the attack continues for a second year (Sipayung et al., 1989; Sudharto, 1998). Heavy incidence of infestation leads to complete defoliation, resulting in a short period of time in the burnt appearance of the palms (Kochu Babu \& Kalidas, 2004) and a decrease in the production of up to 93\% (Pahan, 2006). Currently, the major tool for controlling this pest in oil palm plantations are environmentally unfriendly broad-spectrum insecticides. Intensive use of insecticides has a negative effect on environmental sustainability, pest resistance, resurgence, outbreaks of secondary pests and extinction of non-target insects, such as natural enemies and pollinating insects (Aktar et al., 2009; Noor Farehan et al., 2013; Becker \& Liess, 2015). Therefore, several methods of biological control focusing on the rearing and releasing of natural enemies for suppressing defoliator pests are regarded as more efficient than using insecticides as it costs less and there are fewer social and ecological problems (Garcia \& Ricalde, 2013; van Zyl \& Malan, 2014; Tomson et al., 2017).

Reduviid predators are polyphagous and important natural enemies of several defoliating pests (Sahayaraj, 2014). Sycanus is a predacious reduviid that has a wide prey diet including several orders of insects, such as both the larvae and pupae of Lepidoptera, Coleoptera and Diptera (Sahayaraj \& Balasubramanian, 2016) and is considered to have the potential to be a biological control agent. Several species of Sycanus have been studied as biological control agents of the defoliator pests in oil palm plantations 
(Kalshoven, 1981), such as S. dichotomus Stål (Singh, 1992; Zulkefli et al., 2004; Syari et al., 2010; Jamian et al., 2016), S. macracanthus Stål (Tiong, 1996) and S. collaris (Jamjanya et al., 2014).

$S$. annulicornis Dohrn (Hemiptera: Reduviidae) is one of the Sycanus species commonly found in several agroecosystems in Indonesia, such as soybean and rice ecosystems (Kalshoven, 1981) and in oil palm plantations (pers. observ.), but is not reported as a biological control agent of the nettle caterpillar, either in the laboratory or the field. Kalshoven (1981) mentions that $S$. annulicornis attacks large caterpillars and Helopeltis bugs. This accords with our observation in the laboratory that $S$. annulicornis can attack the last instar of $S$. asigna, which has a body length of up to $3.5 \mathrm{~cm}$ (1 cm longer than $S$. annulicornis adults) and other caterpillars with body lengths up to $5.0 \mathrm{~cm}$ (twice the longth of $S$. annulicornis adults) (Fig. S5). This indicates that this predatory insect has the potential to be used as a biological control agent to control $S$. asigna.

Due to the intensive use of insecticides for controlling the $S$. asigna pests, predatory insects, including $S$. annulicornis, are rarely found in the field. The scarcity of predatory insects, especially when outbreaks of the nettle caterpillar occur, means pest control based solely on the natural abundance of predatory insects cannot be relied upon. Hence, predators must be mass reared in large quantities if biological control is to be successful. One of the problems in the mass production of this predatory insect is an inherent problem associated with producing sufficient prey for the predator. Different species of prey can influence the biology of the predatory insects reared on them (George et al., 1998; Mendes et al., 2002; Zulkefli et al., 2004; Chandral \& Sinazer, 2011; Syari et al., 2011; Ahmad \& Kamarudin, 2016) and their predatory ability in terms of the target pest (van Alphen \& Jervis, 1996; Lv et al., 2016). Currently, there is little information on an appropriate species of prey for rearing of $S$. annulicornis in the laboratory and the ability of $S$. annulicornis to attack and kill S. asigna is unknown. Therefore, in order to find a suitable prey for rearing $S$. annulicornis with a strong tendency to attack and kill $S$. asigna, we evaluated the biological characteristics and predatory ability of $S$. annulicornis in terms of $S$. asigna when reared on different species of prey, i.e., Tenebrio molitor L. larvae (Coleoptera: Tenebrionidae) and Crocidolomia pavonana F. larvae (Lepidoptera: Crambidae).

\section{MATERIAL AND METHODS}

\section{Source and rearing of prey T. molitor}

T. molitor larvae used in this study were obtained from a traditional bird market in Bandung, West Java Province, Indonesia. The larvae were reared in the laboratory using a plastic container (width: $30 \mathrm{~cm}$, length: $50 \mathrm{~cm}$, height: $30 \mathrm{~cm}$ ) using bran as the source of food and a medium. A cabbage leaf was placed on top of the bran as a source of moisture. The pupae were transferred into a new plastic container to avoid cannibalism of pupae by the larvae and kept until beetle emergence. Once a mating couple of beetles were observed, they were moved to a new container containing bran. Eggs with hardened shells were obtained after 3-4 d. Eggs laid by female beetles were collected. After the eggs hatched into larvae, the larvae were reared to the $11^{\text {th }}-12^{\text {th }}$ instar, and then used in this study as prey for $S$. annulicornis.

\section{C. pavonana}

C. pavonana larvae used in this study were collected from cabbage crops in Balai Penelitian Tanaman Sayuran (Balitsa), Lembang, West Java Province, Indonesia. The larvae were reared in the laboratory until they developed into pupae in a plastic container (width: $30 \mathrm{~cm}$, length: $50 \mathrm{~cm}$, height: $30 \mathrm{~cm}$ ) using cabbage leaves as a source of food. The pupae were collected and placed in a new plastic container until the moths emerged. A $10 \%(\mathrm{v} / \mathrm{v})$ honey solution in small cotton wool balls was provided as a supplementary food for the moths. Egg batches laid by the moths on cabbage leaves were collected daily and transferred to a new container where they were kept until they hatched. Newly emerged larvae were reared on a diet of cabbage leaves to the $3^{\text {rd }}$ instar and then used as a prey for $S$. annulicornis.

\section{Rearing / maintenance of S. annulicornis}

The adult males and females of $S$. annulicornis were collected from soybean plantations at Bogor, West Java Province, Indonesia $\left(6^{\circ} 33^{\prime} 6^{\prime \prime} \mathrm{S}\right.$ and $\left.106^{\circ} 44^{\prime} 44^{\prime \prime} \mathrm{E}\right)$. They were individually reared in plastic containers (diameter $5 \mathrm{~cm}$ and height $6.5 \mathrm{~cm}$ ) on $11^{\text {th }}-12^{\text {th }}$ instar larvae of the mealworm, T. molitor, under laboratory conditions (temp. $26 \pm 2{ }^{\circ} \mathrm{C}, 65 \pm 5 \% \mathrm{rh}$, and $12 \mathrm{~L}: 12 \mathrm{D}$ photoperiod. The males and females were allowed to mate in the rearing containers. The eggs laid by the females were collected, separated and placed in new containers with wet cotton swabs for maintaining optimum humidity (75\%) and a $10 \%(\mathrm{v} / \mathrm{v})$ of honey solution in cotton wool was provided as a supplementary food. The nymphs that hatched from these eggs were the $1^{\text {st }}$ generation (F1) nymphs used in this experiment.

\section{Biological parameters of $S$. annulicornis reared on different type of prey}

The newly emerged $1^{\text {st }}$ generation (F1) nymphs were gently separated soon after eclosion and reared individually in new rearing containers (diameter $5 \mathrm{~cm}$ and height $6.5 \mathrm{~cm}$ ), in order to avoid cannibalism, on either a diet of T. molitor larvae (the $11^{\text {th }}$ to $12^{\text {th }}$ instar) or C. pavonana larvae (the $3^{\text {rd }}$ instar). Five prey per nymph were provided daily and the prey consumed were replaced daily with new larvae. The containers with the nymphs were provided with wet balls of cotton wool for maintaining an optimum humidity $(75 \%)$ and a $10 \%(\mathrm{v} / \mathrm{v})$ of honey solution in a small cotton wool ball as a supplementary food. The cotton swabs were changed periodically in order to prevent fungal attack. The nymphs were reared under the same laboratory conditions as described above until adult emergence. Six days after adult emergence, the males and females were allowed to mate. Mated females were subsequently separated and maintained in a rearing container until they laid eggs. Egg batches laid by $1^{\text {st }}$ generation females reared on T. molitor and C. pavonana were collected and used in the experiment. Three batches of eggs from each dietary treatment ( $T$. molitor larvae or $C$. pavonana larvae) were used. Each batch of eggs was kept individually in a container along with wet cotton wool swabs and monitored daily. Newly hatched $1^{\text {st }}$ instar nymphs from each batch of eggs were the $2^{\text {nd }}$ generation nymphs and were individually reared on the same prey diet as the $1^{\text {st }}$ generation. The biological parameters recorded during the growth and development of the $2^{\text {nd }}$ generation nymphs were: (a) the development time of each nymphal stage, (b) adult longevity, (c) sex ratio and (d) egg development (fecundity, fertility and egg incubation period). Twenty males and females from each treatment were randomly selected to be kept until they died in order to 
record adult longevity. Sex ratio was the average of the total number of females to the total number of males that emerged from the same egg batches. To obtain the data on egg development, virgin males and females were allowed to mate in the rearing containers 6 days after emergence. The length of time for which they copulated was recorded. After copulation, mated females were kept individually in order to record the number of egg batches laid during their lifespan. The number of eggs in each batch (fecundity) was carefully counted under a stereomicroscope at a magnification of $40 \times$. The incubation period was the time from egg laying to egg hatch. The fertility of the eggs was determined by counting the number of nymphs emerging from each batch of eggs.

\section{Consumption of prey and growth of $\mathbf{S}$. annulicornis}

The daily consumption of each species of prey was evaluated for all the nymphal stages and adults (male and female) of $S$. annulicornis over a period of 7 days, each based on 13 replicates. Observations were made daily by counting the number of prey consumed and replacing them with fresh specimens from the stock cultures. The daily consumption of prey was determined by dividing the average total number of prey consumed by 7 . The growth of $S$. annulicornis was recorded by weighing the nymphs and adults on an analytical balance (OHAUS PA244) 10 days after emergence.

\section{Ability of $S$. annulicornis as a predator of $S$. asigna}

The predatory ability of both males and females of $S$. annulicornis reared on different species of prey (T. molitor and C. pavonana) was tested by providing them with $4^{\text {th }}$ instar larvae of $S$. asigna in the laboratory. Each of eight of the predators reared on $T$. molitor larvae and C. pavonana larvae, respectively, were randomly selected and starved for $24 \mathrm{~h}$. These predators were individually placed in a plastic rearing container (diameter of $11 \mathrm{~cm}$ and height of $6 \mathrm{~cm}$ ) and allowed to move undisturbed for $10 \mathrm{~min}$ before prey were provided. Each of the predators were provided with three larvae of $S$. asigna over a period of 5 days. The number of $S$. asigna larvae killed was recorded and then replaced with living larvae every $24 \mathrm{~h}$.

\section{Data analysis}

Individual nymphal development times, adult longevities and body weights of $S$. annulicornis, reared on different species of prey, were compared using one-way analysis of variance (ANOVA), and the differences among the treatments tested using Duncan's multiple range test (DMRT). The numbers of prey consumed by the nymphs and adults of $S$. annulicornis and the total number of $S$. asigna killed by male and female $S$. annulicornis, reared on different species of prey, were also analyzed using oneway ANOVA and DMRT. Data on the sex ratio, egg development (fecundity, fertility and egg incubation period), and duration of copulation of $S$. annulicornis, reared on different species of prey, were compared for the 2 treatments using an independent twosample $t$ test. All analyses were performed using IBM SPSS statistics software version 16.0 for windows (SPSS Inc., Chicago, USA). All statistical analyses were carried out at $5 \%$ level of significance $(\alpha=0.05)$.

\section{RESULTS}

\section{Biological parameters}

Results revealed that the different species of prey differently affected the nymphal development time, adult longevity, sex ratio, and egg development of $S$. annulicornis reared in the laboratory. The details of the developmental times of each of the nymphal stages, adult longevity, sex ratio, egg incubation period, fecundity and fertility are presented in Table 1. The nymphs reared on larvae of $C$. pavonana throughout their development had a mean total nymphal period of $74.0 \pm 7.3$ days, which was significantly shorter $(t=3.05, d f=35, P<0.01)$ than those reared on the larvae of $T$. molitor $(80.1 \pm 5.3$ days), except for the $1^{\text {st }}$ instar, which had a significantly longer developmental time $(F=8.205, d f=199, P<0.01)$. S. annulicornis adults reared on $C$. pavonana lived significantly longer than the adults reared on $T$. molitor $(F=28.791, d f=79, P<0.01)$. The males reared on $C$. pavonana lived longer $(81.0 \pm 9.0$ days) than the females (64.8 \pm 12.4 days) and vice versa as the males reared on $T$. molitor lived for a shorter period ( $44.0 \pm 16.7$ days) than the females ( $52.6 \pm 14.4$ days $)$. The sex ratio of $S$. annulicornis reared on both species of prey was female biased ( $1: 1.2$ and $1: 1.9$ reared on $T$. molitor and $C$. pavonana, respectively) and the different species of prey significantly influenced the sex ratio of $S$. annulicornis $(t=9.73, d f=4, P<0.01)$.

The males and females were allowed to mate 6 days after emergence and 7 days after mating, females started laying batches of eggs on the gauze sides of the rearing container. There were no significant difference between the two diets in terms of either the number of egg batches laid per female, which ranged from 1-4 or mean fecundity with an average of $105 \pm 38$ eggs per batch $(t=1.63, d f=49, P<$ $0.5)$. Each egg was glued vertically to the substratum and covered by a white glue-like substance that protected the eggs from dehydration (Fig. S1). The fertility of eggs laid by females reared on $T$. molitor was significantly higher $(70.2 \pm 21.3 \%)$ and they developed faster $(14.1 \pm 3.2$ days incubation) compared to those laid by females reared on C. pavonana, which had a fertility of only $48.5 \pm 20.1 \%(t$ $=2.74, d f=26, P<0.05)$ and incubation period of $20.3 \pm$ 1.7 days $(t=5.74, d f=18, P<0.01)$. As shown in Fig. 1 , duration of copulation of $S$. annulicornis adults reared on C. pavonana $(7.3 \pm 4.1 \mathrm{~min})$ was significantly shorter than

Table 1. Biological parameters, nymphal development time, adult longevity, sex ratio, egg incubation period, fecundity and fertility of S. annulicornis reared on different species of prey in the laboratory.

\begin{tabular}{|c|c|c|}
\hline \multirow{2}{*}{ Biological parameter } & \multicolumn{2}{|c|}{ Prey } \\
\hline & T. molitor & C. pavonana \\
\hline \multicolumn{3}{|c|}{ Nymph (development time, day) ${ }^{* *}$ : } \\
\hline $1^{\text {st }}$ instar & $14.3 \pm 1.6^{b c}$ & $18.5 \pm 4.5^{\mathrm{de}}$ \\
\hline $2^{\text {nd }}$ instar & $15.8 \pm 2.5^{c}$ & $12.5 \pm 4.3^{a b}$ \\
\hline $3^{\text {rd }}$ instar & $15.0 \pm 4.0^{c}$ & $15.3 \pm 4.9^{c}$ \\
\hline $4^{\text {th }}$ instar & $15.7 \pm 3.2^{c}$ & $11.3 \pm 3.1^{a}$ \\
\hline $5^{\text {th }}$ instar & $19.3 \pm 2.5^{e}$ & $16.4 \pm 5.4^{\mathrm{cd}}$ \\
\hline Total nymphal period (day)* & $80.1 \pm 5.3^{a}$ & $74.0 \pm 7.3^{b}$ \\
\hline \multicolumn{3}{|l|}{ Adult: } \\
\hline Male longevity (day) ${ }^{\star \star}$ & $44.0 \pm 16.7^{a}$ & $81.0 \pm 9.0^{c}$ \\
\hline Female longevity (day) $^{\star *}$ & $52.6 \pm 14.4^{b}$ & $64.8 \pm 12.4^{\mathrm{d}}$ \\
\hline Sex ratio (male : female) ${ }^{*}$ & $1: 1.2^{\mathrm{a}}$ & $1: 1.9^{b}$ \\
\hline Egg incubation period (day)* & $14.1 \pm 3.2^{\mathrm{a}}$ & $20.3 \pm 1.7^{b}$ \\
\hline Fecundity (egg)* & $97.1 \pm 38.8^{a}$ & $114.4 \pm 36.4^{a}$ \\
\hline Fertility $(\%)^{*}$ & $70.2 \pm 21.3^{a}$ & $48.5 \pm 20.1^{\mathrm{b}}$ \\
\hline
\end{tabular}

Means \pm SD followed by a different letter for each biological parameter, are significantly different $(P<0.05)$. ${ }^{*}$ Data was analyzed using independent $t$-tests. ${ }^{* *}$ Data was analyzed using one-way ANOVA, followed by DMRT analysis. 


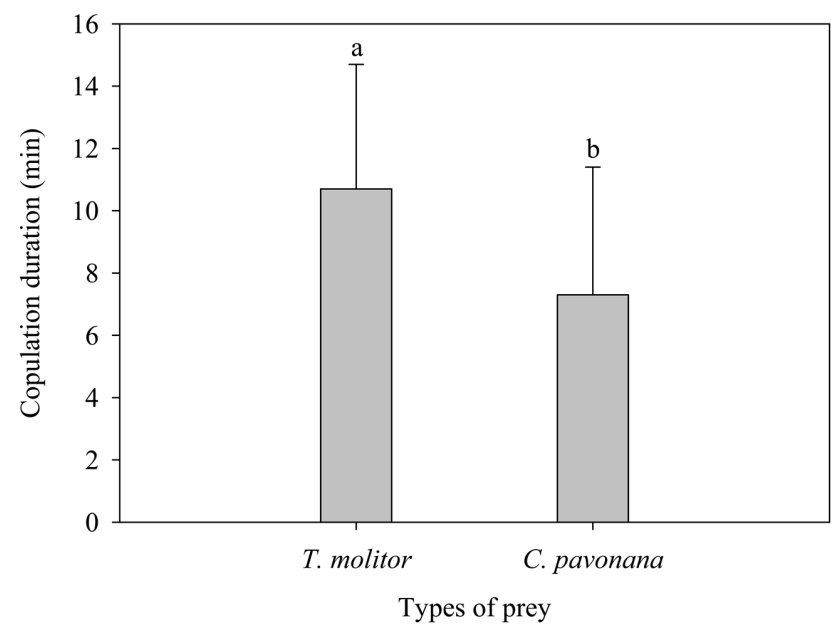

Fig. 1. Mean ( \pm S.D.) duration of copulation of $S$. annulicornis depending on the prey they were reared on. Bars with different letters are significantly different (Indifferent two sample $t$-test, $P<0.05$ ).

that recorded for adults reared on $T$. molitor $(10.7 \pm 4.0$ $\min )(t=1.88, d f=18, P<0.05)$.

\section{Prey consumption and growth of S. annulicornis}

The daily consumption of prey by nymphs and adults of S. annulicornis is summarized in Table 2 . The $1^{\text {st }}$ to $3^{\text {rd }}$ instar nymphs of $S$. annulicornis consumed more larvae of C. pavonana than of $T$. molitor $(F=174.506 ; d f=181 ; P<$ $0.01)$, but the consumption of the larvae of the two species of prey by $4^{\text {th }}$ and $5^{\text {th }}$ nymphs of $S$. annulicornis did not differ significantly. The mean number of prey consumed by males $(1.91 \pm 0.64$ larvae and $1.80 \pm 0.32$ larvae for $T$. molitor and C. pavonana, respectively) and females (3.29 \pm 0.22 larvae and $2.91 \pm 0.29$ larvae for $T$. molitor and $C$. pavonana, respectively) differed significantly in both treatments $(P<0.01)$. The numbers of the different species of prey consumed by males did not differ significantly, but the females of $S$. annulicornis consumed more larvae of $T$. molitor than C. pavonana. In this study, we also recorded a difference in the trend in the consumption of prey by $S$. annulicornis fed on different prey species. S. annulicornis fed T. molitor (Fig. S3) exhibited a gradual increase in the total number of prey consumed during each nymphal stage from

Table 2. Daily consumption of prey by the nymphs and adults of $S$. annulicornis $(n=13)$.

\begin{tabular}{lcc}
\hline \multirow{2}{*}{ Developmental stages } & \multicolumn{2}{c}{ Prey } \\
\cline { 2 - 3 } & T. molitor & C. pavonana \\
\hline Nymph: & $0.28 \pm 0.11^{\mathrm{a}}$ & $0.62 \pm 0.22^{\mathrm{bc}}$ \\
$1^{\text {st }}$ instar & $0.35 \pm 0.16^{\mathrm{a}}$ & $0.61 \pm 0.13^{\mathrm{bc}}$ \\
$2^{\text {nd }}$ instar & $0.46 \pm 0.1^{\mathrm{ab}}$ & $0.63 \pm 0.15^{\mathrm{bc}}$ \\
$3^{\text {rd }}$ instar & $0.60 \pm 0.10^{\mathrm{bc}}$ & $0.65 \pm 0.15^{\mathrm{bc}}$ \\
$4^{\text {th }}$ instar & $0.90 \pm 0.32^{\mathrm{d}}$ & $0.81 \pm 0.21^{\mathrm{cd}}$ \\
$5^{\text {th }}$ instar & & \\
Adult: & $1.91 \pm 0.64^{\mathrm{e}}$ & $1.80 \pm 0.32^{\mathrm{e}}$ \\
Male & $3.29 \pm 0.22^{\mathrm{g}}$ & $2.91 \pm 0.29^{\mathrm{f}}$ \\
Female &
\end{tabular}

Means \pm SD followed by the same letter are not significantly different $(P<0.05)$ based on a one-way ANOVA followed by DMRT analysis.

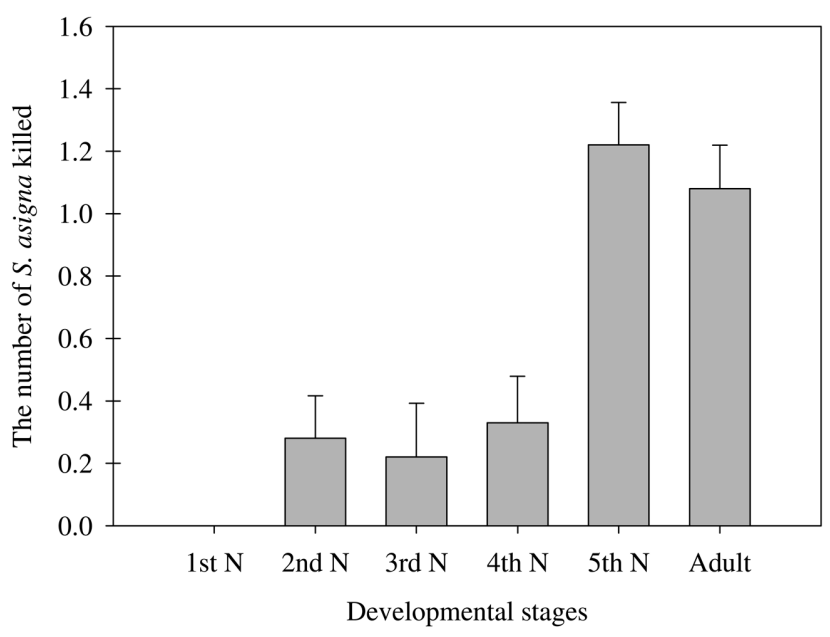

Fig. 2. Mean ( \pm S.D.) number of $S$. asigna larvae killed in $24 \mathrm{~h}$ by nymphs $(\mathrm{N})$ and adults of $\mathrm{S}$. annulicornis.

the $1^{\text {st }}$ instar to the $5^{\text {th }}$ instar. The $1^{\text {st }}$ and $2^{\text {nd }}$ instar nymphs fed on $T$. molitor consumed up to 1-4 larvae per nymph over 7 days, then increased up to 2-5 larvae per nymph during the $3^{\text {rd }}$ and $4^{\text {th }}$ instars, and increased up to 3-10 larvae per nymph during the $5^{\text {th }}$ instar over 7 days (Table S1). Conversely, S. annulicornis fed on C. pavonana (Fig. S2) showed a constant prey consumption rate (2-7 larvae per nymph) in all nymphal stages (Table S2). A significant increase in the number of prey consumed was recorded also in the adult stage (Table 2). To understand the correlation between the number of prey consumed and the growth of this predatory insect, we measured the increase in body weight of $S$. annulicornis at each developmental stage as presented in Table 3 . No significant difference was recorded in the body weight of the $1^{\text {st }}$ to $3^{\text {rd }}$ instar nymphs fed on T. molitor and the body weight of the $1^{\text {st }}$ and $2^{\text {nd }}$ instar nymphs fed on $C$. pavonana, but significant increases in the body weight were recorded in the $4^{\text {rd }}$ instar nymphs fed on $T$. molitor and the $3^{\text {rd }}$ instar nymphs fed on C. pavonana. The increases in body weights of the $3^{\text {rd }}$ to $5^{\text {th }}$ instar nymphs and adults of $S$. annulicornis fed on $C$. pavonana were significantly faster than those fed on T. molitor $(F=$ 528.158; $d f=279 ; P<0.01)$.

Table 3. Body weights (mg) of the nymphs and adults of $S$. annulicornis reared on different species of prey in the laboratory $(n=20)$.

\begin{tabular}{lcc}
\hline \multirow{2}{*}{ Developmental stages } & \multicolumn{2}{c}{ Prey } \\
\cline { 2 - 3 } & T. molitor & C. pavonana \\
\hline Nymph: & $1.3 \pm 0.4^{\mathrm{a}}$ & $1.1 \pm 0.4^{\mathrm{a}}$ \\
$1^{\text {st }}$ instar & $3.3 \pm 1.0^{\mathrm{a}}$ & $2.7 \pm 0.9^{\mathrm{a}}$ \\
$2^{\text {nd }}$ instar & $12.1 \pm 2.7^{\mathrm{a}}$ & $34.5 \pm 9.0^{\mathrm{b}}$ \\
$3^{\text {rd }}$ instar & $38.6 \pm 6.1^{\mathrm{b}}$ & $84.5 \pm 31.0^{\mathrm{c}}$ \\
$4^{\text {th }}$ instar & $81.3 \pm 19.1^{\mathrm{c}}$ & $114.4 \pm 23.3^{\mathrm{d}}$ \\
$5^{\text {th }}$ instar & & \\
Adult: & $122.5 \pm 11.0^{\mathrm{d}}$ & $140.6 \pm 15.7^{\mathrm{f}}$ \\
Male & $251.8 \pm 27.9^{\mathrm{e}}$ & $309.9 \pm 42.5^{\mathrm{g}}$ \\
\hline Female &
\end{tabular}

Means \pm SD followed by the same letter are not significantly different $(P<0.05)$ based on a one-way ANOVA followed by DMRT analysis. 


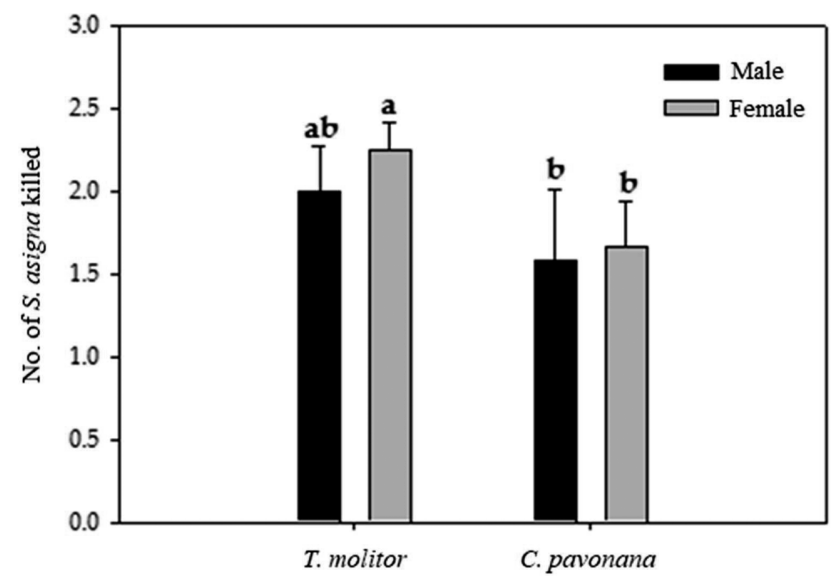

Fig. 3. Mean ( \pm S.D.) numbers of $S$. asigna larvae killed in $24 \mathrm{~h}$ by adults (male and female) of $S$. annulicornis reared on different types of prey. Bars with the same letter are not significantly different (one-way ANOVA followed by DMRT analysis, $P<0.05$ ).

\section{Ability of S. annulicornis as a predator of larvae of S. asigna}

The results of the preliminary study evaluating the ability of all nymphal stages and adults of $S$. annulicornis to attack and kill $4^{\text {th }}$ instar larvae of $S$. asigna are shown in Fig. 2. Data shows that the $1^{\text {st }}$ instar of $S$. annulicornis did not prey on $S$. asigna during the experiment, but the $2^{\text {nd }}$ and $3^{\text {rd }}$ instar were able to prey on $S$. asigna after 4 days exposure to the prey (Table S3). The $4^{\text {th }}$ instar was able to prey on $S$. asigna after 1-3 days exposure to the prey, whereas the $5^{\text {th }}$ instar and adults preyed on $S$. asigna within a day (Table S3, Fig. S4 and video in Suppl. S2). The number of $S$. asigna killed by $5^{\text {th }}$ instar nymphs was higher than that killed by adults (i.e., 1-3 larvae per day for the $5^{\text {th }}$ instar and 1-2 larvae per day for adults). The evaluation of the predatory ability of adults of $S$. annulicornis reared on different species of prey revealed no significant difference in the predatory ability of males and females $(F=4.278$; $d f$ $=15 ; P<0.05)$. S. annulicornis reared on T. molitor can attack as many as 2.2 larvae of $S$. asigna per day, which is more than those reared on $C$. pavonana, which only attack 1.7 larvae of $S$. asigna per day (Fig. 3).

\section{DISCUSSION}

S. annulicornis was capable of completing its nymphal development when fed both species of prey. In this study, the species of prey influenced several biological parameters of $S$. annulicornis, such as nymphal developmental time, adult longevity and sex ratio, which are the relevant biological parameters for the mass production of a predatory insect. The species of prey had a differential effect on the developmental time of each nymphal stage of $S$. annulicornis. The $1^{\text {st }}$ instar nymphs fed on T. molitor developed faster than those fed on C. pavonana, but in the following instars those fed on $C$. pavonana developed significantly faster. This was most likely due to differences in the nutrient requirements of each nymphal stage, particularly for survival during the $1^{\text {st }}$ instar stage and for growth and development in subsequent nymphal stages. Morales-Ramos et al. (2014) show that different species of arthropods, including $T$. molitor and $C$. pavonana, may have different nutritional compositions, in particular, in terms of the ratio of carbohydrate, lipid and protein, which can affect the development of their insect predators.

Ahmad \& Kamarudin (2016) also report that Sycanus dichotomus (Hemiptera: Reduviidae) reared on the larvae of Corcyra cephalonica Stainton (Lepidoptera) have a shorter developmental period than when reared on larvae of T. molitor (Coleoptera). Differences in the nutrient composition of each species of prey not only affects the development of insect predators, but also their survival and reproduction (Huang et al., 2013; Bong et al., 2014; Lv et al., 2016). We recorded that males and females of $S$. annulicornis reared on $C$. pavonana lived longer than those reared on T. molitor. These results are consistent with those of previous studies that report that lepidopteran prey can increase survival and shorten the development of generalist predators (Ambrose et al., 1990; Eubanks \& Denno, 2000). Insect predators with a long adult survival and short developmental time are more suitable for mass rearing (Sahayaraj, 2004) and releasing as biological control agents for suppressing pest populations in the field.

Srikumar et al. (2014) report a significant difference in the longevity of males and females, but in the present study, there were no consistent differences in the longevity of the male and female reduviids reared on the different species of prey. Males of S. annulicornis reared on the lepidopteran $C$. pavonana lived longer than the females, conversely, females of $S$. annulicornis reared on the coleopteran T. molitor lived longer than the males. Females living longer than males is a common feature of most reduviids (Ambrose et al., 1990, 2007; Saharayaj \& Paulraj, 2001; Saharayaj, 2002; Srikumar et al., 2014; Shanker et al., 2016; Nitin et al., 2017), but males living longer than females is also reported for the reduviid Sycanus aurantiacus reared on the coleopteran Tenebrio molitor (Yuliadhi et al., 2015) and Amphibolus venator Klug reared on the coleopteran Tribolium confusum (Youssef \& Abd-Elgayed, 2015). The longevity of adult predatory insects may be significantly affected by the species of prey they feed on as adults (Jervis \& Copland, 1996). A different effect was recorded for the sex ratio. Adults reared on both species of prey (T. molitor and C. pavonana) had a female-biased sex ratio. Female-biased sex ratios are reported in the Reduviidae (Ambrose \& Claver, 1997). The highly female-biased sex ratio and long longevity of adult $S$. annulicornis makes this species more suitable for mass culture because female-biased sex ratio can result in multiple mating's by males and an enhanced fecundity. Van den Assem (1996) assumes that the longer a male can live, the more likely it is that females will be inseminated by males and more eggs fertilized and the longer a female lives the more eggs she will lay.

No significant difference was recorded in the number of eggs laid by $S$. annulicornis reared on the different species of prey. Mated females of $S$. annulicornis reared on both species of prey can lay 1-4 egg batches throughout their 
lifespan, which is similar to that reported for Sycanus dichotomus by Zulkefli et al. (2004), but the number of eggs per batch (fecundity) was higher (105 \pm 38 eggs per batch) compared to that for $S$. dichotomus, which only ranges from 15 to 119 eggs per batch (Syari et al., 2011). Sycanus aurantiacus lays more batches of egg, ranging between 5-11 batches of egg, during its lifespan, but its fecundity is much lower at only 35-73 eggs with an incubation period of 12-14 days (Yuliadhi et al., 2015). Ambrose et al. (2006) reports that the Reduviidae that lay a high number of egg batches have significantly lower fecundities and fertilities. Even though, in this study, the fecundity of $S$. annulicornis was not affected by the species of prey, the fertility of the eggs was significantly affected. Fertility is the more important parameter in mass rearing of predatory insects, as it determines the number of individuals in the next generation. Both male and female contribute to the production of each offspring. The sperm transmitted from the male to the female during mating, is stored by females in a spermathecae to be used for fertilization of the eggs at the time of oviposition (van den Assem, 1996). Thus, the amount of sperm in the spermathecae can affect the fertility of the eggs laid by females. The fertility of eggs laid by females reared on C. pavonana was significantly lower and had a longer incubation period than those laid by females reared on $T$. molitor. We suggest that this is related to the shorter duration of copulation recorded for S. annulicornis reared on $C$. pavonana, which resulted in less sperm being transferred to the females. Fricke et al. (2015) state that duration of copulation is affected by the diet of males during their immature stages. Males with a good prospect of multiple mating, particularly in situations in which the sex ratio is highly female biased, might adjust the allocation of their ejaculates (sperm) over time and between females (Fricke et al., 2015). However, in this study, each male and female was only allowed to mate once, so the potential for multiple mating by males of $S$. annulicornis reared on $C$. pavonana should be further evaluated as it may enhance the fertility of the eggs laid by their mates. Li et al. (2014) report that mating dramatically reduces male longevity in Echinothrips americanus. Therefore, we suggest that a short duration of copulation and its associated lower energy costs will result in the males living longer.

The energy source for survival, growth, development and reproduction of $S$. annulicornis was the prey it consumed. We recorded that the number of prey consumed and the body weight gained by $S$. annulicornis reared on two species of prey differed significantly depending on the species of prey and the developmental stage. The $1^{\text {st }}$ and $2^{\text {nd }}$ instar nymphs consumed over 7 days more $C$. pavonana (2-6 larvae) than T. molitor (1-4 larvae). This was due to the $1^{\text {st }}$ and $2^{\text {nd }}$ instar nymphs have difficulty in paralyzing T. molitor larvae that have harder cuticles and move faster compared to the slow moving soft-bodied lepidopteran larvae. Interestingly, we did not find similar differences in the weight gains of the nymphs indicating that the nymphs were able to channel the energy they acquired mainly into survival and nymphal development rather than into growth (body weight), which is expensive in terms of energy. Coleopteran larvae contain a higher proportion of carbohydrate, which is important for the survival and development of an insect at the beginning of each stadium (Bong et al., 2014; Morales-Ramos et al., 2014), so, even though few larvae of T. molitor were consumed by the $1^{\text {st }}$ and $2^{\text {nd }}$ instar nymphs, they were able to survive and develop into the next nymphal stage. We also recorded that although the $1^{\text {st }}$ and $2^{\text {nd }}$ instar nymphs killed more larvae of $C$. pavonana they only partially consumed them. Therefore, we assume that this insect can adjust its nutritional needs depending on the nutritional characteristics of their prey.

A significant increase was recorded in the number of prey consumed by the $5^{\text {th }}$ instar nymphs and adults due to their greater energy requirement for growth and the subsequent reproduction of the adults. S. annulicornis gained more body weight when reared on larvae of C. pavonana, most likely because they are rich in the proteins required for their growth. Saharayaj et al. (2016) report that the total protein content of Rhynocoris marginatus (Heteroptera: Reduviidae) was higher when it was reared on lepidopteran larvae, which indicates they are a better quality food for Reduviidae. Females of S. annulicornis consumed more prey than males, which is presumably to meet their reproductive needs for egg production. This is supported by a previous study on another species of Reduviidae showing that female $R$. marginatus consume more food than males (Saharayaj, 2008; Saharayaj et al., 2016). Duran Prieto et al. (2016) and Lv et al. (2016) suggest that female predatory insects consume more prey to produce more offspring. However, the greater consumption of prey did not affect the longevity of the predators. Surprisingly, even though the females $S$. annulicornis reared on T. molitor consumed more prey than those reared on $C$. pavonana, the gain in body weight of the former was significantly lower. Mendes et al. (2002) report that Orius insidiosus (Hemiptera: Anthocoridae) consumes more nymphs of Aphis gossypii than eggs of Anagasta kuehniella, due to the lower nutritional quality of the former, so the increase in the consumption of low quality of prey might compensate for their poor quality. It is reasonable to postulate that the greater consumption of prey by females is associated with the need to support reproduction, which is a major factor determining their fitness. Thus, it also makes sense if female $S$. annulicornis consume more T. molitor larvae in order to obtain sufficient energy for egg production and survival when reared on this poor quality prey.

To be an effective biological control agent, S. annulicornis must be an effective predator of the main target pest, $S$. asigna. Inability of a $1^{\text {st }}$ instar nymph to kill $S$. asigna was most likely due to the relative size of $S$. asigna, which is much larger. The $2^{\text {nd }}, 3^{\text {rd }}$ and $4^{\text {th }}$ instar nymphs were able to attack the larvae of $S$. asigna, although they needed more time to recognize and accept $S$. asigna as prey. We found that $5^{\text {th }}$ instar nymphs were better predators than adults, however, they are less effective in the field as they lack wings, which makes it difficult for them to reach pests on the high leaves of oil palm. Consequently, we used adults 
of $S$. annulicornis when evaluating its predatory ability in the laboratory. The species of prey supplied as food during the growth and development of $S$. annulicornis influenced its ability as a predator of the main target, $S$. asigna. The $S$. annulicornis adults reared on $T$. molitor killed more $S$. asigna per $24 \mathrm{~h}$ than those reared on C. pavonana. We suggest that this could be due to an habituation to the prey supplied during the growth and development of the predator. Due to the difference in the characteristics of the prey, especially its speed of movement and the hardness of its cuticle, S. annulicornis exhibited different behaviours when paralyzing the two species of prey. We frequently observed that $S$. annulicornis that fed on T. molitor often left this prey after piercing, because it induced the prey to make rapid movements as a form of self-defence, and subsequently the predator re-pierced and sucked the paralyzed prey or attacked another larva. In contrast, S. annulicornis can more easily pierce and paralyze the larvae of $C$. pavonana as they remain motionless and are soft-bodied. This is similar to the results of Saharayaj et al. (2016) for the reduviid Rhynocoris marginatus, which is also generally faster in capturing lepidopteran larvae than coleopteran larvae. Therefore, the consumption of T. molitor larvae by $S$. annulicornis in which they leave the prey they kill unconsumed or partially consumed was assumed to affect its ability as a predator of $S$. asigna. So, T. molitor larvae are considered to be a potential prey for producing this predatory insect as biocontrol agent of $S$. asigna.

This study demonstrates that it is possible to rear successfully the predatory bug, $S$. annulicornis, on both the larvae of C. pavonana (Lepidoptera) and T. molitor (Coleoptera), but that it has different biological parameters when reared on these two species of prey. The present study revealed that rearing a generalist insect predator on only one species of prey results in a predator that does not have all the requisites for the successful mass production of a biological control agent, including high reproductive rate, long survival, strong predatory ability and synchronization with the prey (pest). Therefore, we recommend rearing a generalist predator, such as $S$. annulicornis, on a combination of different species of prey consisting of both a lepidopteran and a coleopteran so as to meet all the nutritional needs for the development and survival of $S$. annulicornis as well as it resulting in the development of a strong predator of the target pest, $S$. asigna. This recommendation is based on the finding that the growth and development of Sycanus dichotomus is enhanced if reared on a combination of both lepidopteran and coleopteran larvae rather than a single species of prey (Ahmad et al., 2011). Grundy et al. (2000) also report that the assassin bug Pristhesancus plaginnis develops and reproduces better when reared on a combination of prey consisting of suitable proportions of a lepidopteran (Helicoverpa armigea Hubner) and coleopteran (Tenebrio molitor L.). In addition, the evaluation of their ability as a predator of the main target pest, S. asigna, in the laboratory also revealed that $S$. annulicornis is a potential biological control agent of this oil palm pest, however, this needs to be evaluated under greenhouse conditions and in the field before it is utilized in either inundative or augmentative release programmes. In summary, the present study could serve as a guideline for the mass rearing of the predatory bug $S$. annulicornis for use in biological control of the nettle caterpillar pest in oil palm plantations.

ACKNOWLEDGEMENTS. We gratefully acknowledged the financial support provided by the Ministry of Research,Technology and Higher Education, of the Republic of Indonesia, by funding a Hibah Penelitian Disertasi Doktor.

\section{REFERENCES}

Ahmad S.H. \& Kamarudin N. 2016: Growth and longevity of the insect predator, Sycanus dichotomus Stål (Hemiptera: Reduviidae) fed on live insect larvae. - J. Oil Palm Res. 28: 471-478.

Ahmad S.N., Kamarudin N. \& MasiJan Z. 2011: Mixed prey as a food source for mass rearing of the bagworm predator, Sycanus dichotomus. In: Malaysian Palm Oil Board (MPOB) Information Series No. 486. Kuala Lumpur, 4 pp.

Aktar M.W., Sengupta D. \& Chowdhury A. 2009: Impact of pesticides use in agriculture: their benefits and hazards. - Interdiscip. Toxicol. 2: 1-12.

Ambrose D.P., Saju T. \& Sahayaraj K. 1990: Prey influence on the development, reproduction and size of assassin bug, Rhynocoris marginatus. - Environ. Ecol. 8: 280-287.

Ambrose D.P. \& Claver M.A. 1997: Functional and numerical response of the reduviid predator Rhynocoris fuscipes (Fab.) (Heteroptera: Reduviidae) to control leafworm Spodoptera litura (F.) (Lepidoptera: Noctuidae). - J. Appl. Entomol. 121: 331-336.

Ambrose D.P., Kumar S.P., Nagarajan K., Das S.S.M. \& RaviCHANDRAN B. 2006: Redescription, biology, life table, behavior and ecotypism of Sphedanolestes minusculus Bergroth (Hemiptera: Reduviidae). - Entomol. Croat. 10: 47-66.

Ambrose D.P., Gunaseelan S.K., Singh J.V., Ravichandran B. \& Nagarajan K. 2007: Redescription, biology and behaviour of a harpactorine assassin bug Endochus migratorius Distant. Hexapoda 14: 12-21.

BECKER J. \& Liess M. 2015: Biotic interactions govern genetic adaptation to toxicants. - Proc. R. Soc. (B) 282: 20150071, 8 pp.

Bong L.-J., Neoh K.-B., LeE C.-Y. \& JAAL Z. 2014: Effect of diet quality on survival and reproduction of adult Paederus fuscipes (Coleoptera: Staphylinidae). - J. Med. Entomol. 51: 452-459.

Chandral S. \& Sinazer R.L. 2011: Influence of prey on the development and reproduction of Endochus inornatus Stål. - J. Biopestic. 4: 112-117.

Cock M.J.W., Godfray H.C.J. \& Holloway J.D. 1987: Slug and Nettle Caterpillars. The Biology, Taxonomy and Control of the Limacodidae of Economic Importance on Oil Palms in Southeast Asia. CAB International, Wallingford, $270 \mathrm{pp}$.

Duran Prieto J., Trotta V., Fanti P., Castane C. \& Battaglia D. 2016: Predation by Macrolophus pygmaeus (Hemiptera: Miridae) on Acyrthosiphon pisum (Hemiptera: Aphididae): Influence of prey age/size and predator's intraspecific interactions - Eur. J. Entomol. 113: 37-43.

Eubanks M.D. \& DENNo R.F. 2000: Health food versus fast food: the effects of prey quality and mobility on prey selection by a generalist predator and indirect interactions among prey species. - Ecol. Entomol. 25: 140-146.

Fricke C., Adler M.I., Brooks R.C. \& Bonduriansky R. 2015: The complexity of male reproductive success: effects of nutrition, morphology, and experience. - Behav. Ecol. 26: 617624. 
Garcia F.R.M. \& RicAlde M.P. 2013: Augmentative biological control using parasitoids for fruit fly management in Brazil. Insects 4: 55-70.

George P.J.E., SReenivasagan R. \& Kannan S. 1998: Influence of prey species on the development and reproduction of Acanthaspis siva Distant (Heteroptera: Reduviidae). - Entomon 23: 69-75.

Grundy P.R., Maelzer D.A., Bruce A. \& Hassan E. 2000: A mass-rearing method for the assassin bug Pristhesancus plagispennis (Hemiptera: Reduviidae). - Biol. Contr. 18: 243-250.

Huang H., Xu X.N., Lv J.L., Li G.T., Wang E.D. \& GaO Y.L. 2013: Impact of proteins and saccharides on mass production of Tyrophagus putrescentiae (Acari: Acaridae) and its predator Neoseiulus barkeri (Acaro: Phytoseiidae). - Biocontr. Sci. Technol. 23: 1231-1244.

Jamian S., Norhisham A., Ghazali A., Zakaria A. \& Azhar B. 2016: Impacts of 2 species of predatory Reduviidae on bagworms in oil palm plantations. - Insect Sci. 24: 285-294.

Jamuanya T., SiRi N. \& Phanphinit S. 2014: Life history of assassin bug, Sycanus collaris (Hemiptera: Reduviidae) and its efficacy to control insect pests. - Khon Kaen Agr. J. 42: 2557 [in Thai, English abstr.].

Jervis M.A. \& Copland M.J.W. 1996: The life cycle. In Jervis M.A. \& Kidd N. (eds): Insect Natural Enemies: Practical Approaches to their Study and Evaluation. 1st ed. Chapman \& Hall, London, pp. 63-154.

Kalidas P. 2012: Pest problems of oil palm and management strategies for sustainability. - Agrotechnology S11: 001, 3 pp.

KaLSHOVEN L.G.E. 1981: The Pests of Crops in Indonesia (revised and translated in English by P.A. Van der Laan). P.T. Ichtiar Baru/Van Hoeve, Jakarta, xix $+701 \mathrm{pp}$.

Kochu Babu M. \& Kalidas P. 2004: Key pests and diseases of oil palm in India - their biology, epidemiology and method of control. In: Proceeding of the International Conference on the Pests and Diseases of Importance to the Oil Palm Industry, Malaysia, 18-19 $9^{\text {th }}$ May 2004. pp. 184-206.

LAY T.C. 1996: Integrated pest management of leaf-eating caterpillars of oil palms in Sabah. - Planter 72: 395-405.

Li X.-W., Jiang H.-X., Zhang X.-C., Shelton A.M. \& Feng J.-N. 2014: Post-mating interactions and their effects on fitness of female and male Echinothrips americanus (Thysanoptera: Thripidae), a new insect pest in China. - PLOS ONE 9(1): e87725, 7 pp.

Lv J., YAng K., Wang E. \& Xu X. 2016: Prey diet quality affects predation, oviposition and conversion rate of the predatory mite Neoseiulus barkeri (Acari: Phytoseiidae). — Syst. Appl. Acarol. 21: 279-287.

Mendes S.M., Bueno V.H.P., Argolo V. \& Silveira L.C.P. 2002: Type of prey influence biology and consumption rate of Orius insidiosus (Say) (Hemiptera, Anthocoridae). - Revta Bras. Entomol. 46: 99-103.

Morales-Ramos J.A., Rojas M.G. \& Coudron T.A. 2014: Artificial diet development for entomophagous arthropods. In: Morales-Ramos J.A., Rojas M.G. \& Shapiro-Ilan D.I. (eds): Mass Production of Beneficial Organisms: Invertebrates and Entomopathogens. 1st ed. Academic Press, San Diego, CA, pp. 203-240.

Nitin K.S., Shivarama Bhat P., Raviprasad T.N. \& Vanitha K. 2017: Biology, behaviour and predatory efficiency of Sycanus galbanus Distant (Hemiptera: Reduviidae: Harpactorinae) recorded in Cashew plantation. - J. Entomol. Zool. Stud. 5: $524-530$.

Noor Farehan I., Syarafina R. \& Idris A.B. 2013: Toxicity of three insecticides on the predator of oil palm leaf-eater pests
Sycanus dichotomus Stål (Hemiptera: Reduviidae). — Acad. J. Entomol. 6: 11-19.

Pahan I. 2006: Complete Guide of Oil Palm, Agribusiness Management from Upstream to Downstream. Penebar Swadaya, Jakarta, pp. 185-186.

SAHARAYAJ K. 2002: Small scale laboratory rearing of a reduviid predator, Rhynocoris marginatus Fab. (Hemiptera: Reduviidae) on Corcyra cephalonica Stainton larvae by larval card method. - J. Centr. Eur. Agr. 3: 137-147.

SahayARAJ K. 2004: Reduviids in biological control. In Sahayaraj K. (ed.): Indian Insect Predators in Biological Control. Daya, Delhi, pp. 134-176.

SAHARAYAJ K. 2008: Approaching and rostrum protrusion behaviour of Rhynocoris marginatus on three prey chemical cues. - Bull. Insectol. 61: 233-237.

SahaYARAJ K. 2014: Reduviids and their merits in biological control. In Sahayaraj K. (ed.): Basic and Applied Aspects of Biopesticides. Springer Science + Business Media, pp. 195-209.

Sahayaraj K. \& Balasubramanian R. 2016: Reduviid: An important biological control agent. In Artificial Rearing of Reduviid Predators for Pest Management. Springer, Singapore, pp. $1-28$.

Saharayaj K. \& Paulraj M.G. 2001: Rearing and life table of reduviid predator Rhynocoris marginatus Fab. (Het., Reduviidae) on Spodoptera litura Fab. (Lep., Noctuidae) larvae. - J. Appl. Entomol. 125: 321-325.

Sahayaraj K., Muthu Kumar S. \& EnKegaard A. 2016: Response of the reduviid bug, Rhynocoris marginatus (Heteroptera: Reduviidae) to six different species of cotton pests. Eur. J. Entomol. 113: 29-36.

Shanker C., Lydia C., Sampathkumar M., Sunil V. \& Katti G. 2016: Biology and predatory potential of Rhynocoris fuscipes (Fabricius) (Hemiptera: Reduviidae) on the rice leaffolder Cnaphalocrocis medialis (Guenee). - J. Rice Res. 9: 47-49.

SINGH G. 1992: Management of oil palm pests and disease in Malaysia in 2000. In Aziz A., Kadar S.A. \& Barlon H.S. (eds): Pest Management and the Environment in 2000. CAB International, Wallingford, pp. 195-212.

Sipayung A., Desmier de Chenon R. \& Sudharto P. 1989: Recent work with viruses in the biological control of leaf eating caterpillars in North Sumatra, Indonesia. In Jalani B.S. et al. (eds): Proc. of the Int. Oil Palm Dev. Conference - Agriculture, K. Lumpur, Malaysia, 5-9 September 1989. Palm Oil Res. Inst., Kuala Lumpur, pp. 285-293.

Srikumar K.K., Bhat P.S., Raviprasad T.N., Vanitha K., Saroj P.L. \& Ambrose D.P. 2014: Biology and behaviour of six species of Reduviids (Hemiptera: Reduviidae: Harpactorinae) in a Cashew Ecosystem. - J. Agr. Urban Entomol. 30: 65-80.

SudHaRto P. 1998: Utilization of Eliza test for study of infection and dispersal of b Nudaurelia virus on nettle caterpillar Setothosea asigna van Eecke. In Proceedings of the 1998 International Oil Palm Conference, Nusa Dua, Bali. 11 pp.

Syari J., Muhamad R., Norman K. \& Idris A.B. 2010: Feeding behavior and predatory efficiency of assassin bug, Sycanus dichotomus Stål on oil palm bagworm, Metisa plana Walk. Malays. Appl. Biol. 39: 51-55.

Syari J., MuHAMAd R., Norman K. \& IDRIS A.B. 2011: Laboratory rearing of Sycanus dichotomus Stål (Hemiptera: Reduviidae), insect predator of oil palm bagworm, Metisa plana Walker (Lepidoptera: Psychidae). — Sains Malays. 40: 1129-1137.

TIONG R.H.C. 1996: The regulatory roles of natural enemies of some oil palm insect pests. - J. Planter. 72: 653-666.

Tomson M., Sahayaraj K., Kumar V., Avery P.B., McKenzie C.L. \& Osborne L.S. 2017: Mass rearig and augmentative biological control evaluation of Rhynocoris fuscipes (Hemiptea: 
Reduviidae) against multiple pests of cotton. - Pest Manag. Sci. 73: 1743-1752.

van AlPhen J.J.M. \& Jervis M.A. 1996: Foraging behaviour. In Jervis M.A. \& Kid N. (eds): Insect Natural Enemies: Practical Approaches to Their Study and Evaluation. Chapman \& Hall, London, pp. 1-62.

VAN DEN Assem J. 1996: Mating behaviour. In Jervis M.A. \& Kid N. (eds): Insect Natural Enemies: Practical Approaches to Their Study and Evaluation. Chapman \& Hall, London, pp. 63-154.

van ZyL C. \& Malan A.P. 2014: The role of entomopathogenic nematodes as biological control agents of insect pests, with emphasis on the history of their mass culturing and in vivo production - Afr. Entomol. 22: 235-249.

Youssef N.A. \& ABd-ElgaYed A.A. 2015: Biological parameters of the predator, Amphibolus venator Klug (Hemiptera: Reduviidae) preying on larvae of Tribolium confusum Duv. (Coleoptera: Tenebrionidae). — Ann. Agr. Sci. 60: 41-46.
Yuliadhi K.A., Supartha I.W., Wijaya I.N. \& Pudjinto 2015: Characteristic morphology and biology of Sycanus aurantiacus Ishikawa et Okajima sp. nov. (Hemiptera: Reduviidae) on the larvae of Tenebrio molitor L. (Coleoptera: Tenebrionidae). J. Biol. Agr. Healthcare 5: 5-8.

Zulkefli M., Norman K. \& BasRi M.W. 2004: Life cycle of $S y$ canus dichotomus (Hemiptera: Pentatomidae) a common predator of bagworm in oil palm. - J. Oil Palm Res. 14: 50-56.

Received November 21, 2017; revised and accepted March 26, 2018 Published online May 3, 2018

Supplementary files:

S1 (http://www.eje.cz/2018/019/S01.pdf). Figs S1-S5 and Tables S1-S3.

S2 (http://www.eje.cz/2018/019/S02.3GP). Video sequence showing Sycanus annulicornis feeding on the caterpillar of $\mathrm{Se}$ tothosea asigna. 